\title{
Mining the Gap: Physically Integrated Performance and Kinesthetic Empathy
}

\section{Wanda Strukus}

At the core of the theatrical experience we find, always, the relationship between audience and performer. Historically, we have used varying approaches to interrogate this relationship, such as phenomenology, semiotics, and performance studies, and seized upon different terms to mark its existence, including intersubjectivity, identification, standing-in, projection, and empathy. Interdisciplinary studies in theatre and cognitive science provide yet another approach for delving into this issue.

Due, in part, to a hypothesized link between empathy, the human mirror neuron system, and autism, the question of how we come to understand one another in the world has received a great deal of attention within the cognitive science community. The resulting studies and findings offer alternative tools for understanding kinds of empathies in performance. In reciprocal fashion, performance offers controlled circumstances through which to examine empathy, especially if we consider the performance event as a potential site for empathic practice. Empathy is a broad term, encompassing a wide range of the possible ways in which we understand one another. The narrow focus of this essay is kinesthetic empathy, conceptualized as an automatic, involuntary, kinesthetic response of one body to another. ${ }^{1}$ The concept of kinesthetic empathy is problematic because early applications seemed to promote universalist assumptions about response and experience while neglecting a host of cultural, historical, and contextual differences. ${ }^{2}$ Today, we acknowledge that the factors that shape our ability to understand or connect with one another are numerous and complex. In this essay, I propose that cultural and historic factors are shaped and reshaped by embodied experience, and that the unconscious, neural foundations of kinesthetic empathy exist in a dynamic and influential relationship to these other forces.

Kinesthetic empathy is the feeling of sharing another person's movement, or vicariously experiencing another person's movement simply by watching, and it is the focus of much current interdisciplinary work in dance and cognitive science. ${ }^{3}$ The modern conceptualization of kinesthetic empathy is attributed to the philosopher Theodore Lipps and his 1908 essay "Einfühlung, innere

\footnotetext{
Wanda Strukus holds a PhD from Tufts University and teaches dance history, theatre history, and acting at Northeastern University. She is a Boston-based director, choreographer, and producer of site-specific performance and a frequent participant in the ASTR working group in Cognitive Science in Theatre and Performance.
} 
Nachahmung und Organempfindung” ("Empathy, Inner Imitation, and Physical Sensation"). In this essay, Lipps examines the phenomenon of internally imitating the actions of another person simply by observing her, with a particular focus on kinesthetic feeling or muscular tension. " Einfühlung," which David Freedberg and Vittorio Gallese translate perhaps more accurately as "in-feeling" or "feeling into," had been previously used by philosopher Robert Vischer in 1873 to describe the viewer's physical and kinesthetic response when observing a painting. ${ }^{5}$ Both Vischer and Lipps identified the shared kinesthetic experience we now call kinesthetic empathy. ${ }^{6}$ This shared experience has influenced dance theory and criticism since the early twentieth century due to dance critic John Martin's adoption and advancement of the concept. ${ }^{7}$ Kinesthetic empathy is now of particular interest to the primary investigators of The Watching Dance Project, including cognitive scientist Christian Keysers and dance theorist Dee Reynolds, who study the empathic connections between audience and performer. However, the underlying concepts of kinesthetic empathy appear regularly in the work of cognitive scientists such as Vittorio Gallese, who focus on wider applications of empathy, the mirror neuron system, and embodied cognition.

Not all performance hinges on kinesthetic empathy or on an audience member's ability to put herself in the place of the performer (or performer-ascharacter). There are certainly some kinds of performances, however, in which the forging of this empathic connection is the primary goal. In this essay, I look at AXIS Dance Company, an Oakland, California-based, physically integrated dance company that was founded in 1987. As a physically integrated company, AXIS incorporates many differently-abled dancers, and the core company has always included wheelchair dancers. In this respect, AXIS is representative of many physically integrated dance and dance-theatre companies in the United States, the United Kingdom, Australia, and Europe that include both wheelchair dancers and non-wheelchair dancers. AXIS's goals include redefining dance and making it accessible to all, and changing the way an audience thinks about dance and the possibilities of the human body. ${ }^{8}$ Implicit in these goals is a need to make a profound connection with the audience, a connection I cautiously identify as kinesthetic empathy.

A physically integrated performance that includes both disabled and nondisabled performers presents a lived-body experience on stage that may differ significantly from the lived-body experience of nondisabled audience members. ${ }^{9}$ The purpose of physically integrated performance is not always/only a sociopolitical one. However, most physically integrated companies are interested in reducing rather than reinforcing the oppositional and essentialist distinctions of disabled and nondisabled, and rewriting what disability theorist Petra Kuppers calls nondisabled certainties and narratives about disability. ${ }^{10}$ The composition of these companies, featuring performers of different physical abilities, contributes 
to this reduction and rewriting effort, but the critical element in the process is the way the audience engages with the performers in the moment of the performance.

My premise in this essay is that the experience of watching performers with different physical abilities can contribute to changing our perceptions about physical difference. This is not a radical premise, as it is the same one that underlies many physically integrated performances; watching performance involves a level of engagement and exchange that can modify our relationship to the people we are watching. I am not suggesting that watching alone changes perception, or that any such change is uncomplicated or instantaneous. Nor am I suggesting that nonconscious neural activity magically leads to a connection with another person. Gallese, an early discoverer of mirror neurons and a proponent of their role in empathy, notes, "Neurons are not epistemic agents. The only things neurons 'know' about the world are the ions constantly flowing through their membranes." 11 The way we understand one another is a multifaceted cognitive process. However, I am suggesting that there is a fundamental, automatic, kinesthetic way of experiencing or trying to experience similarity and difference, and our understanding of such foundational processes can be valuable in changing our perceptions.

As noted earlier, relationships between individuals of different physical abilities are shaped by a host of factors. Social, cultural, and historical practices and beliefs result from conscious cognitive processes that become so habitual and engrained that they become or seem to become unconscious processes. The processes hypothetically involved in kinesthetic empathy are unconscious and automatic, but may also influence individually held beliefs and practices by either upholding or overturning them. The performance space offers a kind of laboratory in which people of different physical abilities can gather to perform and watch performance. This "laboratory" is not isolated from the outside world, and we bring our previously held assumptions to bear on what we see and do. There is, however, a hypothesis at work here: in this space, there is the opportunity to temporarily bracket those assumptions to allow something else to happen. This essay is about that something else.

\section{Mirror Mechanisms and Their Relationship to Kinesthetic Empathy}

Cognitive explanations for the phenomenological experience of kinesthetic empathy begin with the human mirror neuron system. Mirror neurons were first discovered in the macaque monkey. These neurons are activated when the monkey executes a goal-oriented movement and when the monkey observes another monkey (or person) performing the same movement. Further tests using fMRI showed that analogous brain regions of human beings expressed similar patterns of behavior. Some areas of the human premotor and parietal cortices are active when executing an action and when observing someone else execute 
the same action. Until quite recently the existence of actual mirror neurons in human beings was anticipated but hypothetical. But in early 2010, Roy Mukamel et al. recorded a significant number of individual neurons that responded to both action execution and observation in the human supplementary motor area and the hippocampus and environs. ${ }^{12}$ This "direct, electrophysiological evidence" of human individual mirror neurons was made possible through the cooperation of patients with severe, intractable epilepsy who were undergoing tests that involved placing electrodes in their supplementary motor area (SMA). ${ }^{13}$ Through this electrode placement, Mukamel was able to record activity from 1,177 individual cells. While most data about mirroring systems in human beings will continue to be limited to the more hypothetical information available through fMRI, the documentation of individual neurons with mirroring capabilities provides studies of the human mirror neuron system with a more concrete foundation and reframes the human mirror neuron system as actual rather than speculative. ${ }^{14}$

Observations about the mirror neuron system have led to the hypothesis that our understanding of the inner state of others depends, in part, on implicit motor simulation; when we see someone do something, we automatically activate motor impulses that we would use to do that same action ourselves. This hypothesis has led Christian Keysers et. al to conceptualize the premotor cortex not as a "private fort of our own actions but [rather] a shared arena in which our actions and those of others can coexist." ${ }^{15}$ Keysers's work has focused on mirroring activity that potentially occurs in areas other than the premotor cortex. The somatosensory cortex, associated with touch, and the insula, associated with emotion and the physical expression of emotion, may also function as shared arenas for the experiences of self and others. Keysers's hypotheses are based only on fMRI studies and are in no way definitive. His observations that areas of the somatosensory cortex that respond to touching (BA2) and being touched (SII) also seem to respond when we watch the actions of touching or being touched, however, suggest that the vicarious experience of touching/being touched may be another way in which we understand others. ${ }^{16}$

Mirroring behavior seems to be an integral part of human and primate brain activity, although the quality and degree of mirroring seems to vary greatly among individuals. Movement studies conducted by Beatriz Calvo-Merino and Daniel Glaser have examined such variables as expert movers (professional dancers) versus nonexperts, previously practiced movements versus unfamiliar movements, and gender specific dance movements versus dance movements performed by both genders equally. The results of these studies suggest that our mirroring mechanisms respond more vigorously to movements that we are familiar with and, in particular, movements that we have previously executed. There is also the suggestion that with regard to movements that are gender-coded mirroring mechanisms respond more vigorously when the observer and the executer of the 
movements are the same sex..$^{17}$

Keysers also observed varying responses to stimuli in the somatosensory cortex. In a study that involved watching images of an athlete breaking his leg, one third of the participants reported feeling vicarious pain in their own limb while the remaining two-thirds of the participants felt a generally negative feeling, but no pain. The degree and kind of feeling that the participants reported was supported by observations of fMRI brain activity. Those who felt vicarious pain had activity in SI and SII of the somatosensory cortex and those who did not feel pain did not. $^{18}$

It is not surprising to suggest that some people are more empathic than others. While Keysers's studies are preliminary, thus far his data suggest, “[M]ore empathic people show stronger activation than less empathic people when they perceive the actions of others, synaesthetes who feel the sensations of others activate their somatosensory cortices more strongly than nonsynaesthetes, and lesions in the somatosensory cortices impair our capacity to feel the emotions of others."19 The experience of kinesthetic empathy, and perhaps all forms of empathy, depends on both the stimuli and on the nature of the perceiver.

This essay is not the place to consider in detail the factors that might make a person more or less empathic, but it is important to acknowledge that our individual tendency (if not capacity) for kinesthetic empathy varies widely, and that this variation is yet another difference in the room when we are watching a performance. People who dance or frequently attend dance performances most likely have or have developed a stronger kinesthetically empathic connection to dance movements, just as an athlete, or a person who frequently watches sporting events, may have or have developed a stronger kinesthetically empathic connection to certain athletic movements. Past kinesthetic experience as well as social and cultural influences will play a role in shaping these neural tendencies. While some individuals may be predisposed to feelings of kinesthetic empathy, a premise of this essay and of physically integrated performance is that such feelings and awareness can also be developed.

\section{The Nature of This Exploration}

Physically integrated dance that incorporates wheelchair dancers confronts a societal challenge that is kinesthetic and phenomenological on one hand, and culturally and historically engrained on the other. For the wheelchair user, the wheelchair is incorporated into the body schema as an integral part of the lived body that one moves from and through. For the non-wheelchair user, the wheelchair may be an object or a piece of equipment that a person is in or on, separate from the body itself and symbolic of disability. ${ }^{20}$ "Body schema" refers to a representation of the body that is produced by proprioceptive, vestibular, somatosensory and visual information and is used by the brain to control bodily movements. ${ }^{21}$ The 
body schema is dynamic and constantly updated, accommodating the changes that occur to the body over time. Cognitive scientist Lucilla Cardinali observes that Head and Holmes's 1911 hypothesis that tool use affects plastic changes in the body schema had been widely accepted, despite the absence of proof that the schema was actually modified. Cardinali's own work offers evidence that tool use affects motor arm behavior and the perceived length of the arm even after the tool is removed. ${ }^{22}$ Like a tool, the wheelchair theoretically becomes integrated into the way the wheelchair user experiences the world, and is as likely as any tool to affect plastic changes in the body schema. In her essay on re-embodiment for wheelchair users after spinal cord injury, sociologist Christina Papadimitriou includes first-person narratives while acknowledging that her subjects experience difficulty in verbally expressing "the embodied struggle of incorporating the materiality of the wheelchair into one's general style of being in the world. ${ }^{2{ }^{23}}$ She notes, however, some trends in the narratives of independent-living wheelchair users that suggest the incorporation of the wheelchair into the body schema: "I put my chair on along with my clothes ... it's part of me . . . I forget it," and, "[the chair] is part of me. It's my other half. My mind is one half, the wheelchair is my body." ${ }^{24}$ Alice Sheppard, a dancer with AXIS, expresses a similar feeling regarding her wheelchair: "It's not so much a thing as a real body part." ${ }^{25}$ These samplings are not representative of all wheelchair users, but combined with the observation that tool use affects change in the body schema, they suggest that, at least in some cases, the wheelchair becomes part of the lived-body experience of the world. One of the questions that arises in physically integrated performance is whether different lived-body experiences and different experiences of the body schema create an obstacle to kinesthetic empathy.

In her commentary on a 2009 episode of the television series, Glee, the disability blogger "Wheelchair Dancer" expresses frustration with what seems to be a fundamental kinesthetic misunderstanding. In the episode, the students are asked to spend three hours a day in wheelchairs and perform a wheelchair musical theatre number to find greater empathy for their disabled peer. Wheelchair Dancer writes:

And then there's the sad fact of the [wheelchair] "dancing;" [sic] the choreography sucks.... The rest is notable only for the way that it shows that able-bodied, non-wheelchair-using folk really do think of chairs as bicycles you move with your arms. There's absolutely no body-chair integration at all. They think of sitting in a chair as being only about not being able to move their legs (and in Artie's case as being about having his hips and legs twisted to one side). That mistaken understanding leads to some very weird looking people in chairs. On chairs would be 
a better phrase for it. The fake paralysis of their legs somehow wends its way up their bodies so that they are really only able to push with their elbows (no wonder they have sore arms!)." ${ }^{26}$

The producers of Glee have already incited a battle with the disabled community by casting Kevin McHale, a nondisabled actor, in the role of the wheelchairusing Artie. Misunderstanding the lived-body experience of disability mars the "Wheels" episode, which seems a well-intentioned attempt at inclusiveness. And as Wheelchair Dancer points out, that misunderstanding is first a kinesthetic misunderstanding. Wheelchair Dancer's entry shows that for her, the wheelchair performance of a non-wheelchair user "feels" wrong. She may be having a feeling of kinesthetic empathy (wheelchairs as "bicycles you move with your arms"), but it does not match her experience as an actual wheelchair user. McHale's performance of Artie might fit the imaginative experience (a kind of empathy) of a nondisabled viewer, in the sense that McHale experiences the wheelchair the way any nondisabled person would, but for a "real" wheelchair user, the performance is kinesthetically and experientially "wrong" or inauthentic because the performers use their muscles and body structure in a way that an actual wheelchair user would or could not. Arguably, the producers of Glee and AXIS Dance Company are attempting to do the same thing, which is to establish a bond of kinesthetic empathy between disabled and nondisabled individuals. While Glee's belief that they could accomplish this bond using nondisabled performers is troubling, both the desire and the missing-of-the-mark seem characteristic of nondisabled attempts at empathizing with disability.

When technologies and practices such as the kinesthetic misunderstanding of disability are repeated, they are reinforced, which is one of many reasons that the Glee episode is problematic. ${ }^{27}$ If our mirror neuron system responds more readily and vigorously to what we already know, then difference, particularly the unfamiliar movements of a differently-abled body, may pose a challenge for the mirroring system of our premotor cortex. At the same time, watching a (familiar) nondisabled person pretending to have a disability might kinesthetically reinforce ablist assumptions about the disabled experience of the lived body. Since kinesthetic empathy likely engages both nonconscious and conscious processes, we may not always be aware of the ways in which our perspectives are being reinforced or changed through exposure to movement. The plasticity of the brain allows for change, and the act of merely watching the movement of a differently-abled body may contribute or instigate change, but it seems clear that the movement watched must be authentic to the differently-abled body that performs it.

The material for the ensuing observations is purely qualitative and is drawn from my own experience of watching AXIS in performance, from audience comments, press materials, and interviews. Much of the commentary is taken 
from audience members who elected to attend an AXIS Company lecturedemonstration and/or performance, and to attend a post-show talkback. The comments were made by audience members who were invested enough in the performance to want to learn more about it, and who self-selected as willing to talk about their experience or query the performers about theirs. As such, they are not representative of all audience members. This informal collection of information offers a preliminary exploration of the experience of kinesthetic empathy in physically integrated performance. It cannot definitively determine whether watching movement can change us and to what degree, but it is my hope that this exploration can point toward a more formal study of kinesthetic empathy in physically integrated performance and to strategies for channeling kinesthetic empathy more effectively.

\section{AXIS Dance Company}

AXIS Dance Company, one of the world's most acclaimed and innovative ensembles of performers with and without disabilities, will change the way you think about dance and the possibilities of the human body forever.

-AXIS Dance Company ${ }^{28}$

In 1997, AXIS Dance Company entered its eleventh year and shifted its focus to become a repertory company. The company mission - to create and perform contemporary dance through collaboration with dancers with and without disabilities, to challenge traditional definitions of "dance," "dancer," and "ability" and expand dance to include a community that has been left out of the performing arts, to educate, and to promote physically integrated dance - remained the same, but the artistic directors began commissioning new work from some of the most noteworthy choreographers of the modern dance world, including Bill T. Jones, Joe Goode, David Dorfman, Alex Ketley, Kate Weare, Stephen Petronio, and others. This choice to become a repertory company raised the company's profile and also put it in the position of having to constantly revisit, revise, and develop its movement vocabulary as different choreographers - some who had never worked with a physically integrated company before - came into the studio and began the process of creating dance for differently-abled dancers.

Interrogating one's own movement patterns and exploring the ways we embody our experience may always be integral to the choreographic process, but these strategies become more significant when the choreographer cannot make assumptions about what each dancer and each differently-abled dancer's body can do. Each new choreographer is engaging questions about the nature of dance, virtuosity, composition, and kinesthetic empathy for differently-abled 
bodies, a process related to AXIS's overall mission. At the same time, the dancers are necessarily engaging kinesthetic empathy to understand and execute the choreographer's movement. ${ }^{29}$ This choreographer-dancer exchange becomes a model for the experience of kinesthetic empathy that is intended for the audience as well. In some ways, AXIS, with its ever-changing choreographers, may be more sensitive to (and more primed for) issues of kinesthetic empathy than a company whose work is choreographed by the artistic director or a small pool of choreographers.

\section{AXIS Dance Company in Performance, July 26 and July 30, 2010, Bates Dance Festival}

The three dances presented by AXIS at the Bates Dance Festival on July 30 and also excerpted in the lecture demonstration on July 26 were Joe Goode's 2007 the beauty that was mine, through the middle, without stopping, Alex Ketley's 2008 Vessel, and David Dorfman's 2009 Light Shelter. This particular performance involved four disabled dancers and three non-disabled dancers, and it was clear that all the dancers, while differently-abled, were strong, highly trained, virtuosic, and expressive in their technique. What was also clear to me as I watched was that I was drawn more easily to movement that was familiar to me, either from my experience of watching dance or my own dance training and background.

The movements of the nondisabled dancers were familiar and quickly triggered the typical feelings that I have when watching dance, an experience, as Ann Daly notes, that is both visual and kinesthetic. I had previously watched physically integrated dance, but I had not watched physically integrated dance with wheelchair dancers, and it took some time for me to feel a kinesthetic connection. I was cognitively engaged because I could evaluate and appreciate the choreography and the strength, technique, and performance intensity of the wheelchair dancers. I could enjoy the performance. But I had come to watch, assuming I would automatically feel a kinesthetic empathic bond because I desired one; despite my desire, however, I had to admit to myself that I was caught up more in watching than in feeling.

This weak experience of kinesthetic empathy on my part was not consistent throughout the performance. As I watched over time, I found powerful moments in which I felt connected to all the dancers equally. Those moments invariably involved contact duets (a duet in which the dancers are in frequent physical contact with each other's bodies) or the wheelchair dancers using their wheelchairs in (to me) radical ways, such as tipping over onto one side and sliding or rotating on the floor, tipping forward to balance partially on their hands and pulling themselves across the floor, or moving out of the chair completely, perhaps maintaining contact with it but often moving independently of it. The wheelchair, theoretically a significant aspect of the wheelchair dancer's lived-body experience, seemed to 
be an obstacle to my finding a kinesthetic connection to the dancer, except when he or she was using it in an unconventional (to me) way. But if the wheelchair is part of the wheelchair dancer's body, what does it mean if my stronger kinesthetic response occurred when that part of the body was left behind?

My initial response may be typical. Christina Papadimitriou's interviews with wheelchair users include the follow observations: "People see the wheelchair first, then they see the person in the chair" and "If people see the chair first and the person second, then all you see is disability." ${ }^{30}$ In some cases, from the wheelchair user's perspective, what is seen first by the nondisabled community is the wheelchair, the equipment as equipment, and only afterwards the person, or the person-and-wheelchair as a whole body. If that is the case, there are any number of factors that contribute to it: historically and culturally ingrained beliefs, habit, lack of exposure/familiarity with wheelchair users, vocabulary (as Papadimitriou notes the difference between thinking of someone as "in" a wheelchair rather than being a wheelchair user) ${ }^{31}$ Can watching the way the wheelchair user dances and moves in performance change this way of seeing that seems to be an obstacle to feeling?

In my case, yes. I cannot call what happened while watching this AXIS performance purely kinesthetic empathy because I was engaging other conscious cognitive processes in my desire to monitor my feelings and to increase my connection to the performance. I was, ironically, trying to make something happen that is presumably automatic and involuntary, and herein lies part of the awkwardness of trying to separate and distinguish neural substrates from conscious cognition; I was using conscious processes to try to stimulate unconscious ones. But it is widely accepted that what have been called top-down and bottom-up processes of the brain are reciprocal and by the end of the performance, I felt a stronger kinesthetic connection to all of the performers. As I watched, I began to identify aspects of the AXIS performance that seemed to strengthen my experience of kinesthetic empathy:

1. Contact duets. When a nondisabled dancer whose movements are familiar to me physically interacts with the wheelchair dancer, he or she gives me a way of accessing an unfamiliar and unpracticed movement vocabulary made by a differently-abled body. I may not have a direct feeling of kinesthetic empathy with the wheelchair dancer, but I am having a kinesthetically empathic experience of dancing with the wheelchair dancer, and this potentially leads me toward kinesthetic empathy. In this case, familiar movements are creating a bridge or point of contact with unfamiliar movements.

2. Contact duets, part II: Touch. As I noted earlier, Christian Keysers's work hypothesizes the somatosensory cortex, particularly the areas BA2 and SII, as being potential sites for mirroring mechanisms, and that touching and being touched are also potential places for shared or vicarious experience. Unlike the mirror 
neuron system in the premotor cortex that seems to prefer familiar movement, the hypothetical mirror neuron system of the somatosensory cortex seems less finicky. fMRI studies have shown that SII was active both when watching a person being touched and an object being touched. Keysers hypothesizes that what is shared in this instance is the feeling of being touched. ${ }^{32}$ If this is the case, then body-tobody contact and body-to-wheelchair contact are experienced similarly by this hypothetical mirroring system in the somatosensory cortex. My own experience resonates with this hypothesis. In contact duets, the wheelchair was touched in the same way any other part of the body would be touched; firmly, lightly, pushed, pulled, caressed. In those moments, I experienced the wheelchair as part of the body or bodies involved in the duet rather than as something separate or inorganic to the movement. Touch seems capable of transforming the wheelchair from equipment to lived body.

I observed similar responses to touch and contact duets in the audience, a large percentage of which seemed to have a unified response to a sequence from Joe Goode's the beauty that was mine, through the middle, without stopping. In the sequence in question, company dancers Rodney Bell and Sonsherée Giles lied on their backs with their legs bent in a sitting position and then rolled over to their left side, Bell in a manual wheelchair and Giles without a chair. They lifted their upper bodies, making eye contact and seeing each other as they slid across the floor, and as Bell paused to lie on his side again, Giles stood and stretched out full length across the up-turned, right-side wheel of Bell's chair and began to spin herself gently above him as he slid, rotating beneath her in the opposite direction. ${ }^{33}$ In both the lecture-demonstration and the actual performance, there was an audible, collective intake of breath from the audience. Something intense, and moving, and intimate had happened, and the audience was profoundly connected to it in what seems to have been an immediate and involuntary way. It is impossible to know what actually happened to the observer on the neural level, but my experience and the experience of much of the audience reflects Vischer and Lipps's use of Einfühlung or "in-feeling” to describe the observer's involuntary, shared, kinesthetic response to the aesthetic experience. Much of the audience was kinesthetically responding to a moment of movement that was beautiful, and I suggest that part of what made it beautiful and kinesthetically shared was the engagement of touch.

3. Using the chair in different orientations. When the wheelchair was in an unfamiliar orientation for me (i.e., when a wheelchair dancer was lying on his or her side on the floor), I started to experience the wheelchair differently. The irony is that the wheelchair, which is a primary component of mobility and being-in-the-world for the disabled dancer, became more resonant for me as it became less functional. As Christina Papadimitriou notes, a non-wheelchair user tends to respond to the wheelchair as a functional piece of equipment, and 
these strategies within the dance that remove the wheelchair from its obvious functionality changed my perception and experience of both the chair and the wheelchair dancer. While I may have been merely responding to novelty and to the athleticism of the dancer's technique in these more vigorous movements, these elements of the movement vocabulary created a lived-body experience of the wheelchair that resisted being read as functional. The movement became aesthetic, movement for the sake of movement, in the same way that the dance movement of nondisabled dancers is often aesthetic rather than purely functional. While many early studies of the mirror neuron system focused on goal-oriented movement, it is worth noting that the concept of Einfühlung was first applied to a kinesthetic response to an aesthetic experience, not a functional or goal-oriented one. One aspect of the interdisciplinary work of dance and cognitive science, and of neuroaesthetics in general, is exploring how the aesthetic experience provides cognitive opportunities that are different from everyday life. The wheelchair dancer's inventive, nonconventional, aesthetic movements may provide the audience member with an entrée to a kinesthetic experience and kinesthetic empathy that conventional movement may not. Hypothetically, that shared, if unusual, experience in performance could lead to shared experiences in other situations as well.

\section{The Awkwardness of the Q \& A}

A question-and-answer session following a lecture-demonstration or performance can be a rich opportunity to discover what the audience is actually taking away from the experience, and the degree to which they are empathizing with the performers in the sense of feeling what the performers are feeling. It can also be filled with painfully awkward moments when the shared experience is not as successful as hoped, and when a divide remains between the performer's experience and that of the audience. I attended two AXIS question-and-answer sessions at the Bates Dance Festival, one following the lecture-demonstration on July 26 and one following the July 30 performance.

The audience for the question-and-answer sessions was a mix of people of different physical abilities, but those who actively participated or offered questions to the company, seemed to be people without visible disabilities. At the first session, an audience member gave the most empathic comment of the evening, saying he was already excited about choreographing for the company. Most of the other responses over the course of the two Q \& A's, however, characterized us as audiences still caught in oppositional distinctions between disabled and nondisabled. While the company was thanked and applauded by the Q \& A participants, the compliments were slightly characterized as what Wheelchair Dancer refers to in her blog as cringe-worthy: ${ }^{34} \mathrm{~A}$ dancer in the audience thanked the company because she now knew, if anything ever happened to her body, 
she would still be able to dance. Another audience member complimented the company on its amazing performance, saying that she thought it was going to be scary, but it wasn't. Other questions included: Do you ever forget your limitations while you are dancing or imagine that you can reach beyond them? Do the nonwheelchair dancers worry about being run over? Have you ever considered having a Metropolis-like industrial set, with wheels, so that the wheelchairs would fit in? How do you distinguish between doing "tricks" and dancing?

It is an inevitable part of performance that when one performs, one makes oneself available to the audience for a kind of consumption. After an hour and a half of performance in which the audience has had permission to watch as much as they please, they have a sense of intimacy with the performers, a sense of knowing them, and they will ask questions and feel permitted to ask questions that they might not ask in other contexts. This sense of familiarity may be related to kinesthetic empathy, but it seems to be part of a more complex relationship of consumption and ownership that is outside the bounds of this essay to address. The audience at this performance - like all audiences - is not a homogenous unit, but a group of diverse individuals, however, the questions asked characterize and represent us as a collective unit in this moment. Our questions suggest that there is a gap between what we, as an audience, had kinesthetically experienced, and what the dancers felt and intended to share with us. However, the questions also suggest that we have a strong desire to make a connection with the performers. It is clear that we want to understand. The questions we ask are awkward and possibly offensive, and our ignorance is certainly a cultural ignorance, but once again, I suggest that it is a kinesthetic ignorance as well.

The "trick" question, perhaps, best illustrates the complex fusing of cultural and kinesthetic ignorance that forms an obstacle to kinesthetic empathy, and the way both factors influence the perceptions of performers and audience. Calling something a "trick" suggests a disconnection or alienation from the movement-a trick is something purposefully made to look difficult or virtuosic. A trick is not authentic or honest. An example of a wheelchair dance movement that is sometimes perceived as a "trick" by non-wheelchair users is the "wheelie." Some physically integrated dance companies, such as New York-based Infinity Dance Theatre, have removed the wheelie from their dance vocabulary for this very reason..$^{35}$ The perception of wheelie-as-trick seems most associated with an ablist perspective that views the wheelchair as prop or equipment rather than a part of the body. Papadimitriou's research on the rehabilitation of wheelchair users with spinal cord injuries offers an alternative view from the perspective of wheelchair users and disability therapists:

A "wheelie" is the technique of balancing the wheelchair on its back two wheels, and it is a term that both staff and patients use. 
Staff recommends that SCI in-patients who use non-electrical wheelchairs learn to balance in that position for at least one minute. Teaching patients to do "wheelies" serves, ostensibly, the purpose of being able to "bump" curbs or maneuver inclines. Doing a wheelie requires upper body and arm strength in order for the user to lift the wheelchair onto the two back wheels and balance in that position. Learning to do wheelies is an exercise during physical therapy that manual wheelchair users are expected to have mastered before discharge. It is part of the clients' re-embodiment practices. ${ }^{36}$

The wheelie means something different for a wheelchair user than it does for a non-wheelchair user; as Papadimitriou notes, the wheelie makes certain aspects of embodied life possible that would otherwise not be possible and it must be successfully performed in order for a new wheelchair user to be discharged from a rehabilitation setting. It is a fundamental movement of the manual wheelchair vocabulary, and its presence and meaning in the context of wheelchair dance has a different significance than a non-wheelchair user might attribute to it.

When the participant in the question-and-answer session asked the "trick" question, all of the dancers agreed that this issue is always a danger in all forms of dance. Is the ability to do thirty-two-plus fouettés an act of virtuosity or a trick for the ballet dancer? It is a subjective interpretation based on prior experience, context, factors - such a music and musicality - and kinesthetic empathy. The same is true for wheelies and great shows of strength and dexterity for the wheelchair dancer. The audience participant's question suggests that he was seeing tricks, not dance. Is there something the dancers and choreographers can do to help shift his subjective experience? Is it a question of being exposed to more wheelchair dance in order to become familiar enough with the movement vocabulary to differentiate trick from artistry? Or is it a question of sharing information: Does knowing that a wheelie is one of the fundamental parts of wheelchair movement vocabulary change that perception? The wheelie is an authentic movement, not a trick, but the audience member's misperception may not be remediable through watching alone. It may require a more volitional and conscious aspect of cognition, or new kinesthetic information to change his experience of the dance.

\section{Conclusion, or Seeing Is Not Necessarily Mirroring}

Shaun Gallagher observes that when we hypothesize the mirroring of movement (kinesthetic empathy) as automatic, we find ourselves unable to distinguish movement perception and movement simulation as separate processes. ${ }^{37}$ If mirroring is automatic and integral to human brain behavior, then, indeed, perceiving movement and vicariously experiencing it become the same 
event. In the experience of watching physically integrated dance, however, it is clear that in some cases seeing is not mirroring or simulating, or at least it is not a simulation with any accuracy to the original experience. Phenomenologically, perceiving is not always the simulation of doing, even if there are mechanisms in our brain that tell us that it is.

In terms of kinesthetic empathy and, perhaps, all forms of empathy, we are always limited by our own first-person experience, as both phenomenologists and cognitive scientists have observed. When we watch another's movement, what we simulate is our own experience of the movement, not the experience of the other. There will always be a gap between what we perceive and what we experience. And while it is more pleasant to imagine that the cognitive mechanisms of empathy allow us to truly connect with one another, instead of giving us a very convincing illusion of connecting with one another, knowing that we are always missing the mark is useful information for strengthening empathic bonds. One of the great obstacles to understanding differently-abled bodies (from both ablist and disabled persons' perspectives) is that we already assume that we do understand. In all likelihood, the producers of Glee and the audience participants in the AXIS Q \& A have no idea that their understanding of differently-abled bodies in performance is inaccurate. Their sense of kinesthetic empathy, which is based on what they know and have experienced, is telling them that they do understand, effortlessly and automatically. It is possible that through repeated and careful observation, we might begin to pick up pieces of kinesthetic information that would begin to adjust the accuracy of our shared experience. But that possibility becomes more probable if we know we need to look for our misperceptions.

AXIS Dance Company and many other physically integrated performance companies do not rely solely on watching performance as a strategy for changing perceptions about disability and differently-abled bodies. Performance takes a central role because it is a way to reach a large number of people. But workshops, outreach programs, and community and professional classes that allow dancers and nondancers, both disabled and nondisabled, to work together on movement projects offer more experiential approaches to developing empathy, and these kinds of experiences promote an understanding and awareness that is kinesthetic as well as cultural. In addition, question-and-answer sessions provide information that influences conscious cognitive processes that can, in turn, help to inform and shape an experience of kinesthetic empathy. The automatic experience of kinesthetic empathy is very likely a factor in how we understand and experience both physical difference and physical similarity. But if that automatic experience is providing inaccurate information, we have the resources to adjust the experience through the reciprocal relationship of conscious and nonconscious cognitive processes. The more we understand about the limits and potential of kinesthetic empathy, the more we can mine this gap between our own experiences and those 
of others and use that information to strengthen our empathic relationships.

\section{Notes}

1. For an overview of the broader discussions and complications involving both the term and concept of "empathy," see C. Daniel Batson's, "These Things Called Empathy: Eight Related but Distinct Phenomena," The Social Neuroscience of Empathy, eds. Jean Decety and Wiliam Ickes. 2009. Also, philosopher Shaun Gallagher's How the Body Shapes the Mind (Oxford: Oxford UP. 2005) includes a comprehensive overview of the major theories of empathy. Gallagher promotes a model of empathy that is embodied and interactive, but his ninth chapter, "The Interactive Practice of Mind" is devoted to an explication of the dominant Theory of Mind approaches to understanding empathy, Theory Theory, reading other minds by postulating about other's mental states and explaining and predicting behavior based on that theoretical knowledge, and Simulation Theory in which we use our own mental experience as a model for another person's mind and behavior (206-36).

2. Matthew Reason and Dee Reynolds ("Kinesthesia, Empathy, and Related Pleasures: An Inquiry into Audience Experiences of Watching Dance," Dance Research Journal 42.2 (2010): 49-75) and Susan Leigh Foster ("Kinesthetic Empathies and the Politics of Compassion," Critical Theory and Performance, eds. Janelle Reinelt and Joseph Roach [Ann Arbor: U of Michigan P, 2007]) outline in detail dance critic John Martin's early adoption of the concept of kinesthetic empathy, his universalist assumptions with regard to the observer's experience of watching dance, and his problematic blending of kinesthetic and emotional response.

3. The Watching Dance Project (watchingdance.org) a multidisciplinary initiative cosponsored by four institutions in the United Kingdom, Manchester, Glasgow, and York St. John Universities and Imperial College London, is a significant nucleus for the study of kinesthetic empathy.

4. Theodore Lipps, "Einfühlung, innere Nachahmung und Organempfindung." Archiv für die gesamte Psychologie: 185-204. 1903. Reference in The Virtual Laboratory. Max-Plank-Institute for the History of Science, Berlin. ISSN 1866-4784 - <http://vlp.mpiwg-berlin.mpg.de/>

5. David Freedberg and Vittorio Gallese, "Motion, Emotion, and Empathy in Esthetic Experience," Trends in Cognitive Sciences 11.5 (2007): 198.

6. Psychologist Edward Titchener translated Lipps and Vischer's term "Einfühlung" as "empathy" in 1909, and, while the word empathy now has broad range of intersubjective or shared experiences, it is worth noting that the source of the term initially referred to a shared inner kinesthetic experience. Titchener's translation is cited in most explications of the journey from "Einfühlung" to "empathy," including Freedberg and Gallese (525) and Reason and Reynolds (53).

7. Reason and Reynolds 42.

8. AXIS Dance Company, <http://www.axisdance.org/index.php>.

9. The "lived body experience" is a concept articulated by Edmund Husserl that is fundamental to phenomenology and refers to the body schema, or the individual's experience of her body in the world in a tactile, sensuous, active, and experiential way. From a cognitive science perspective, we would include sensation, perception, and proprioception in the lived-body experience.

10. Petra Kuppers, Disability and Contemporary Performance: Bodies on Edge (New York: Routledge, 2003): 12.

11. Vittorio Gallese, "The Two Sides of Mimesis: Girard's Mimetic Theory, Embodied Simulation and Social Identification," Journal of Consciousness Studies 16.4 (2009): 26.

12. Roy Mukamel, Arne D. Ekstrom, Jonas Kaplan, Marco Iacoboni, and Itzhak Fried, "SingleNeuron Responses in Humans during Execution and Observation of Actions," Current Biology 20.8 (8 April 2010): 750-56.

13. Christian Keysers and Valeria Gazzola, "Social Neuroscience: Mirror Neurons Recorded in Humans," Current Biology 20.8 (27 April 2010): R353-R354.

14. Mukamel et al. 750-56.

15. Christian Keysers, Jon H. Kaas, and Valeria Gazzola, "Somatosensation in Social Perception," Nature Reviews: Neurosicence 11 (June 2010): 417-28. Keysers's study found fMRI activity in the somatosensory cortex when subjects observed touching or being touched as well as when they were touched themselves, and activity in the insula while subjects experienced disgust and when they observed disgust in another person (417). 
16. 423-24. Regarding the action of being touched, Keysers's observations suggest that the neurons in SII respond equally to a person or an object being touched, and that what they respond to is the feeling of being touched, not the nature of the thing being touched.

17. Beatrice Calvo-Merino, C. Jola, D. E. Glaser, and P. Haggard, "Towards a Sensorimotor Aesthetics of Performing Art," Consciousness and Cognition 17.3 (September 2008): 911-22; See also, Calvo-Merino, Julie Grèzes, Daniel E. Glaser, Richard E. Passingham, and Patrick Haggard, "Seeing or Doing? Influence of Visual or Motor Familiarity in Action Observation," Current Biology 16.19 (10 October 2006):1905-10; and, Robert Krulwich, "Monkey Do, Monkey See." Interview with Daniel Glaser, NOVA ScienceNow, PBS, January 2005.

18. Keysers et al. 425. Keyser's study suggests that specific areas of the somatosensory cortex, the primary somatosensory cortex (SI) and the secondary somatosensory cortex (SII) are activated when we perceive others being touched, performing an action, or experiencing pain. The areas described also receive direct input from brain areas that are known to have visual and auditory properties, which offers a possible explanation of the vicarious experience of another person's experience of touch or pain.

19. 426. In Keyser's studies, "more empathic" and "less empathic" people self-identify as such in participant surveys conducted prior to the experiment.

20. As Christina Papadimitriou notes, the wheelchair is so iconic of disability that an image of a person sitting in a wheelchair is used on public signs to signify "disability" on restrooms, entrances, and parking areas (698) ("Becoming En-Wheeled: The Situated Accomplishment of Re-Embodiment as a Wheelchair User after Spinal Cord Injury,” Disability \& Society 23.7 [December 2008]: 691-704).

21. The term "body schema" dates to a 1911 Brain article by Sir Henry Head and Sir Gordon Holmes ("Sensory Disturbances from Cerebral Lesions," Brain 34 [1911-1912]: 102-254).

22. Lucilla Cardinali. "Tool-Use Induces Morphological Updating of the Body Schema," Current Biology 19.12 (2009): 478-79.

23. Papadimitriou 694.

24. 694.

25. Bruce Weber, “A Dance Company Mixes Arms, Legs, and Wheels," New York Times 30 October $2009<$ http://www.nytimes.com/2009/11/01/arts/dance/01sfculture.html? r=1>.

26. "Wheelchair Dancer," “Glee," Wheelchair Dancer Blog 13 November 2009, Web. <http:// cripwheels.blogspot.com/>.

27. Kuppers 13-14.

28. AXIS Dance Company, <http://www.axisdance.org/index.php>; also regularly included in program and press materials.

29. The process of learning and teaching choreography usually involves some elements of understanding and imitating another's movements. Dancers often learn choreography or parts of choreography by watching the choreographer demonstrate the movement and then replicating it. The choreographer notices whether the dancer accurately executes the movement in order to make corrections. I suggest that these processes are essentially ones of kinesthetic empathy accompanied by other conscious cognitive processes.

30. Papadimitriou 698

31. 698 .

32. Keysers et al. 420

33. A video clip of this sequence is viewable at the AXIS Dance Company website, http://www. axisdance.org/performance_repertory.php\# the beauty that was mine, through the middle, without stopping (2007), choreographed by Joe Goode.

34. "Wheelchair Dancer," "Totally Cringe-worthy Dance," Wheelchair Dancer Blog 9 August 2009. Web. <http://cripwheels.blogspot.com/>.

35. Mary Brennan, "Infinity's Number," Infinity Dance Theatre, ed. Rick Stanley. Infinity Dance Theatre, n.d. Web. 3 Dec. 2010.<http://www.infinitydance.com/print9.html>. According to Kitty Lund, founder and artistic director of Infinity Dance, "There are two rules, hard and fast, for this company ... . Two: no wheelies allowed. It's a stereotype. And it's totally apparatus-driven."

36. Papadimitriou 696

37. Shaun Gallagher, How the Body Shapes the Mind (Oxford: Oxford UP, 2005): 223. 
